\title{
Calreticulin exposure on malignant blasts predicts a cellular anticancer immune response in patients with acute myeloid leukemia
}

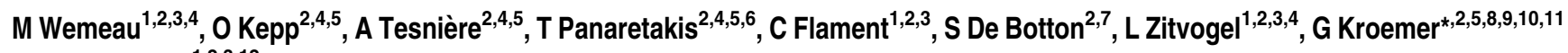 \\ and N Chaput ${ }^{\star, 1,2,3,12}$
}

Experiments performed in mice revealed that anthracyclines stimulate immunogenic cell death that is characterized by the pre-apoptotic exposure of calreticulin (CRT) on the surface of dying tumor cells. Here, we determined whether CRT exposure at the cell surface (ecto-CRT) occurs in human cancer in response to anthracyclines in vivo, focusing on acute myeloid leukemia (AML), which is currently treated with a combination of aracytine and anthracyclines. Most of the patients benefit from the induction chemotherapy but relapse within 1-12 months. In this study, we investigated ecto-CRT expression on malignant blasts before and after induction chemotherapy. We observed that leukemic cells from some patients exhibited ecto-CRT regardless of chemotherapy and that this parameter was not modulated by in vivo chemotherapy. Ecto-CRT correlated with the presence of phosphorylated elF2 $\alpha$ within the blasts, in line with the possibility that CRT exposure results from an endoplasmic reticulum stress response. Importantly, high levels of ecto-CRT on malignant myeloblasts positively correlated with the ability of autologous $T$ cells to secrete interferon- $\gamma$ on stimulation with blast-derived dendritic cell. We conclude that the presence of ecto-CRT on leukemia cells facilitates cellular anticancer immune responses in AML patients.

Cell Death and Disease (2010) 1, e104; doi:10.1038/cddis.2010.82; published online 2 December 2010

Subject Category: Immunity

An optimally efficient anticancer therapy can be achieved by destroying each cancer cell. However, we know that a longlasting disease-free survival is not easy to achieve, presumably because some tumor (stem) cells escape from therapy and may remain dormant for months, years and sometimes decades. One strategy that might improve therapeutic outcome relies on combination of potent cytotoxic chemotherapeutics and the induction of antitumor immune responses that control residual disease.

At the theoretical level, chemotherapy and immunotherapy are difficult to be reconciled because chemotherapy with DNA-damaging agents often induces the massive destruction of immune effectors. Owing to this immunosuppressive side effect, it is intrinsically difficult to elicit immune responses against tumor antigens in patients after several cycles of chemotherapy. ${ }^{1}$ Moreover, apoptosis seems to be the principal cell death mechanism induced by chemotherapy, and apoptosis is mostly viewed as a non-immunogenic (or even tolerogenic) cell death modality. Indeed, billions of cells succumb to apoptosis every day in healthy individuals yet do not provoke any signs of autoimmunity. ${ }^{2}$ However, a recent series of papers has demonstrated that some chemotherapeutic agents, in particular anthracyclines and oxaliplatin, are unique in their capacity to induce immunogenic cancer cell death in mice. These studies unraveled the molecular mechanisms that distinguish immunogenic from non-immunogenic cell death. The immunogenicity of cell death relies on at least three independent events, namely (i) the early exposure of calreticulin (CRT) on the cell surface of stressed cells (ecto$(\mathrm{CRT})^{3}$ and the subsequent (ii) adenosine tri-phosphate (ATP) ${ }^{4}$ secretion and (iii) high mobility group box 1 (HMGB1) release ${ }^{5}$ by dying tumor cells. Membrane-exposed ecto-CRT favors the engulfment of the apoptotic bodies by dendritic cells (DCs), while HMGB1 and ATP modulate DC-mediated tumor antigen presentation and T-cell polarization. ${ }^{4}$ Of note, the vast majority cytotoxic agents fail to induce CRT exposure, while only a few such as anthracyclines and oxaliplatin are able to induce ecto-CRT. Knockdown of CRT, blockade of ecto-CRT or inhibition of the pathway leading to CRT exposure abolishes the immunogenicity of cell death elicited by anthacyclins or oxaliplatin. ${ }^{3}$ Normally, CRT is present in the lumen of the endoplasmic reticulum (ER). In response to

${ }^{1}$ Institut National de la Santé et de la Recherche Médicale, U1015, Villejuif, France; ${ }^{2}$ Institut Gustave Roussy, Villejuif, France; ${ }^{3}$ Centre d'Investigation Clinique en Biothérapie, CIC BT 507, Villejuif, France; ${ }^{4}$ Faculté de Médecine de l'université Paris-Sud XI, Le Kremlin-Bicêtre, France; ${ }^{5}$ Institut National de la Santé et de la Recherche Médicale, U848, Villejuif, France; ${ }^{6}$ Department of Oncology/Pathology, Karolinska Institutet, Stockholm, Sweden; ${ }^{7}$ Département d'Hématologie, Institut Gustave Roussy, Villejuif, France; ${ }^{8}$ Metabolomics Platform, Villejuif, France; ${ }^{9}$ Centre de Recherche des Cordeliers, Paris, France; ${ }^{10}$ Pôle de Biologie, Hôpital Européen Georges Pompidou, AP-HP, Paris, France; ${ }^{11}$ Université Paris Descartes, Paris 5, Paris, France and ${ }^{12}$ Cellular Therapy Unit, Institut Gustave Roussy, Villejuif, France ${ }^{*}$ Corresponding author: N Chaput, Centre d'Investigation Clinique Biothérapie 507, Institut Gustave Roussy, 114 rue Edouard Vaillant, 94805 Villejuif, France. Tel: + 3314211 6616; Fax: + 3314211 6094; E-mail: nathalie.chaput@igr.fr or G Kroemer, INSERM, U848, Institut Gustave Roussy, Pavillon de Recherche 1, 94805 Villejuif, France. E-mail: kroemer@orange.fr

Keywords: calreticulin exposure; acute myeloid leukemia; T cells immunity; anthracyclines

Abbreviations: CRT, calreticulin; DC, dendritic cell; APC, antigen-presenting cell; PBMC, peripheral blood mononuclear cell; HMGB1, high mobility group box 1; ATP, adenosine tri-phosphate; $\operatorname{SIRP} \alpha$, signal-regulatory protein alpha

Received 22.7.10; revised 07.10.10; accepted 08.10.10; Edited by G Melino 
specific ER stresssors, the eukaryotic translation initiation factor $2 \alpha$ (elF $2 \alpha$ ) becomes phosphorylated, thus enabling the so-called integrated stress response that is linked to a translational arrest. $^{6}$ This elF2 $\alpha$ phosphorylation is also essential for CRT exposure because cells that lack the elF2 $\alpha$ kinase, hyperactivate the elF2 $\alpha$ phosphatase or contain a non-phosphorylatable elF $2 \alpha$ mutant fail to expose CRT in response to anthracyclines or oxaliplatin. ${ }^{7,8}$

The induction of $T$ cells responses against leukemic cells has been shown to ameliorate the therapeutic outcome in patients with acute myeloid leukemia (AML) who were treated with allogenic hematopoietic stem cells transplantation (HSCT). ${ }^{9}$ The success of HSCT is linked to a specific immune response, the so-called graft-versus-leukemia reaction in which transplanted $\mathrm{T}$ cells recognize leukemia-specific antigens as well as minor histocompatibility antigens. It has been suspected, yet remains to be confirmed, that natural autologous immune response may influence the clinical course of AML. Thus, antibodies specific for leukemiaassociated antigens (LAAs) have been described, for example, in promyelocytic leukemia. ${ }^{10}$ Specific anti-leukemic T lymphocytes have been identified in a few studies involving AML patients. ${ }^{11}$ It has been suspected that the presence of these specific autologous $T$ lymphocytes predicts a favorable outcome. ${ }^{11}$ Conversely, a high frequency of regulatory $\mathrm{T}$ cells $\left(\mathrm{CD} 4{ }^{+} \mathrm{CD}_{25} 5^{\text {high }} \mathrm{Foxp}^{+}\right.$Treg) is associated with a poor outcome of AML therapy. ${ }^{12}$ As compared with normal volunteers, AML patients possess an elevated frequency of Treg cells, which have an activated phenotype (with an elevated expression of CTLA-4, GITR, perforin and granzyme $B)$, inhibit conventional T-cell proliferation ex vivo via IL-10 and TGF $\beta 1$, and have an elevated capacity to hydrolyze ATP (because of a high expression of the ecto-enzymes CD39 and CD73). ${ }^{12}$

Driven by these premises, we examined ecto-CRT expression on malignant blasts from $\mathrm{AML}$ patients, before and after chemotherapy with anthracyclines. Importantly, we found that a therapy-independent CRT exposure correlated with the specific immune response of $T$ lymphocytes against autologous blast-derived DC. These results underscore the clinical relevance of CRT exposure in the context of cancer immunology.

\section{Results}

\begin{abstract}
AML blasts can expose CRT (ecto-CRT) at their cell surface regardless of chemotherapy. Anthracyclines are capable of inducing immunogenic cancer cell death in mice. ${ }^{2}$ Obeid et al. ${ }^{3}$ showed that anthracyclines induce the translocation of CRT from its orthotopic localization within the lumen of ER vesicles to the surface of tumor cells (ectoCRT). Ecto-CRT is essential for the chemotherapy-mediated induction of adaptive immune responses and the rejection of tumors in mice. We therefore examined the membrane translocation of CRT on malignant blasts from patients treated with anthracyclines. The flow cytometry analysis of CRT expression on blast cells at the diagnosis, before any treatment, revealed significant (with a cut-off of $5 \%$ ) expression of membrane CRT in 10 of the 20 patients
\end{abstract}

(Figure 1a). The percentage of positive cells was rather variable from one patient to the other, ranging from 5 to $95 \%$. In contrast, no upregulation of ecto-CRT expression was observed on malignant blasts after anthracycline-based chemotherapy (Figures $1 b$ and $c$ ), except for two patients (Figure 1b). Similar results were found at different time points for several patients (data not shown), suggesting that CRT exposure reflects a stable alteration of blasts. Moreover, different leukemia cell lines (HL60, K562) or primary AML blasts incubated with anthracylines (either doxorubicin or idarubicin) in vitro for 1 to $4 \mathrm{~h}$, failed to translocate and/or upregulate CRT to the plasma membrane (data not shown). Peripheral blood mononuclear cell (PBMC) from healthy volunteers (HVs) did not display any significant ecto-CRT expression, meaning that $<5 \%$ of normal lymphocytes or monocytes exposed CRT. No clinical or biological characteristic of the AML patients was significantly associated with ecto-CRT expression in terms of age, white blood count or the FAB type (Table 1).

An ELISA assay, which was performed on 16 of the 20 patients' sera, detected high concentrations of soluble CRT, compared with HVs, for 6 of the AML patients, all with high white blood counts. No significant correlation between the CRT concentration and CRT exposure on the membrane of the blasts could be highlighted ( $354 \pm 370$ and $202 \pm 221 \mathrm{ng} / \mathrm{ml}$ for negative and positive ecto-CRT groups respectively, $P>0.05)$. Moreover, no change of CRT concentration before or after chemotherapy could be demonstrated $(275 \pm 300$ versus $180 \pm 200 \mathrm{ng} / \mathrm{ml}$ respectively, $P>0.05)$. In contrast, we detected a positive correlation between serum CRT levels and white blood cell counts $(r=0.5699, P=0.0169)$, which may reflect the spontaneous mortality of malignant blasts or, alternatively, a nonspecific release of CRT from such cells.

The phosphorylation of elF2 $\alpha$ is associated with CRT exposure of on the blasts membrane. The phosphorylation of elF $2 \alpha$ is a crucial event in the molecular pathway that dictates the translocation of ER-resident CRT to the cell surface, ${ }^{8}$ we therefore analyzed the phosphorylation state of malignant blast from AML patients that show spontaneous CRT exposure and those that failed to expose CRT even after treatment. Immunodetection of the phosphoneoepitope using a specific antibody revealed that the spontaneous CRT exposure on malignant blasts was associated with a hyperphosphorylation of elF2 $\alpha$ (Figure 1d).

CD47 expression on leukemic blasts correlates inversely with ecto-CRT. CD47 is an immunoglobulin-like protein that interacts functionally with integrins and thrombspondin-1 (Gao et al. $^{13}$ ) and that participates in functions as diverse as neutrophil migration, ${ }^{14}$ axon extension ${ }^{15}$ and T-cell costimulation. ${ }^{16}$ In addition, CD47 is capable of interacting with its receptor signal-regulatory protein alpha $(\operatorname{SIRP} \alpha)^{17}$ on macrophages to negatively regulate phagocytosis. Blockade of CD47 expression results in phagocytosis of red blood cells, ${ }^{18}$ as well as T cells and whole bone marrow cells in a transplant setting. ${ }^{19}$ Thus, CD47 functions as a 'don't eat me' signal to ensure that autologous cells are not inappropriately phagocytosed. Intriguingly, two recent studies revealed that CD47 is upregulated on leukemia cells ${ }^{20}$ and represent an 

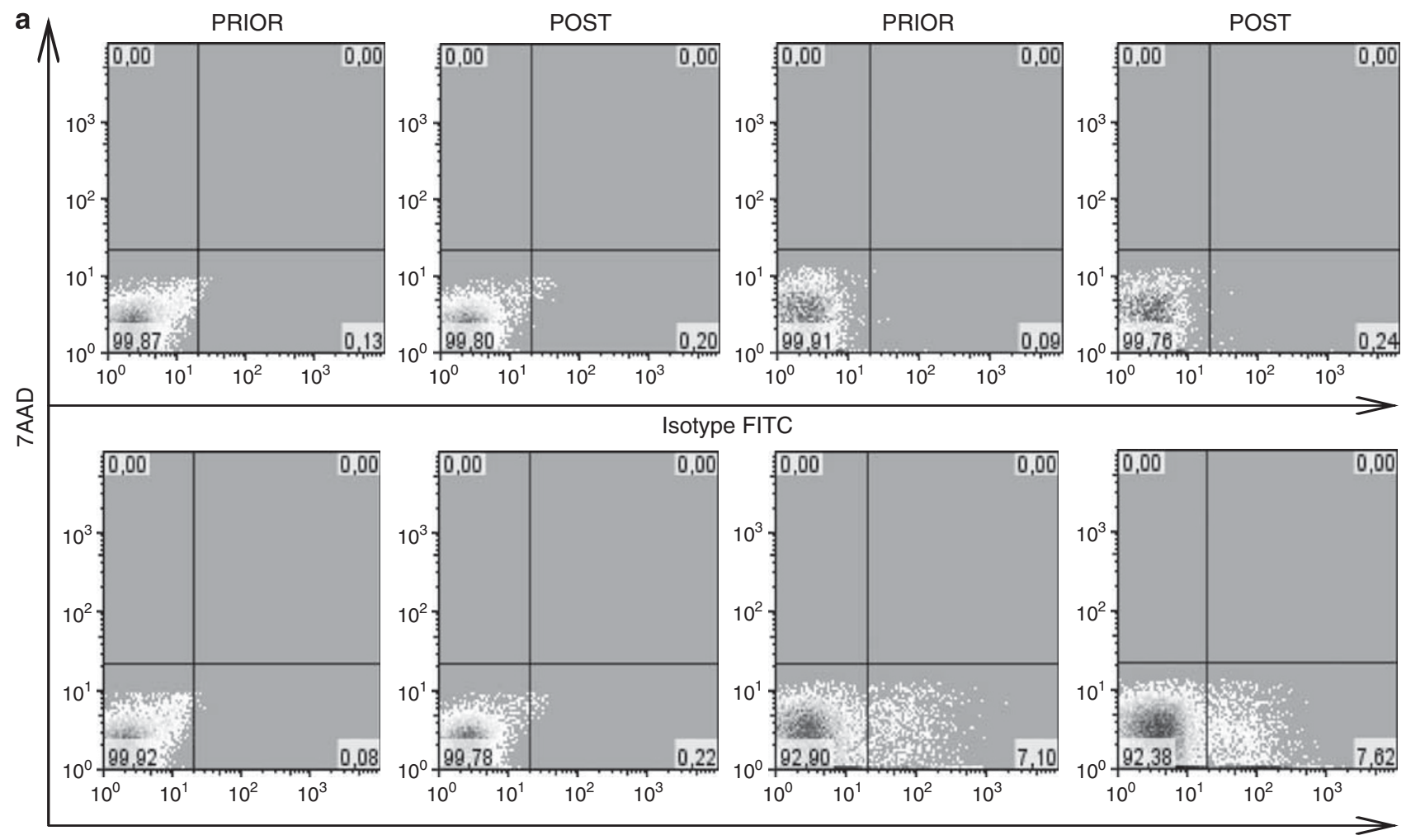

CRT-FITC

b

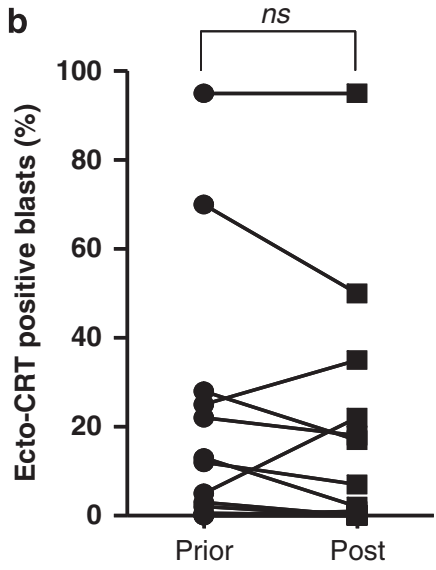

c

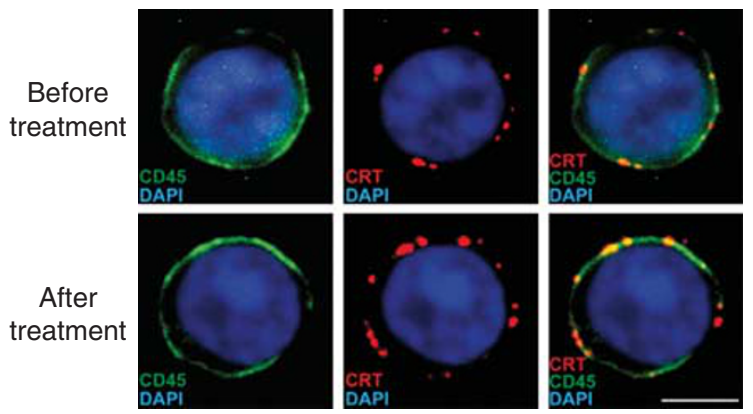

d Ecto-CRT

$37 \mathrm{kDa}$

$37 \mathrm{kDa}$

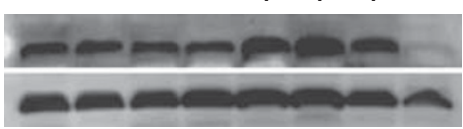

elF2 $\alpha-p$

elF2 $\alpha$

Figure 1 Malignant myleoblasts from some AML patients spontaneously express CRT on their cell surface (ecto-CRT). (a) Representative FACS analyses of one patient whose blasts do not express ecto-CRT, neither before nor after treatment (right panel), and another patient whose blasts express ecto-CRT even before treatment (left panel). (b) Percentages of blasts expressing ecto-CRT, analyzed by flow cytometry on blood samples before chemotherapy (previous) and 2-6h after chemotherapy. Statistical analysis was performed using Wilcoxon's test on matched pairs. (c) CRT exposure (red) has been evaluated in CD45-positive blast (green) from blood samples before and after chemotherapy by immunostaining and subsequent confocal microscopy. Nuclei (blue) have been stained with DAPI. Scale bar represents $2 \mu \mathrm{m}$. (d) Blasts from different patients have been analyzed for their elF2 $\alpha$ phosphorylation state. A representative immunoblot depicting the phospho-elF2a and is shown. A polyclonal antibody detecting a different epitope has been used to ensure equal loading

adverse prognosis factor in AML. ${ }^{21}$ Confirming these data, we found that in our cohort that CD47 expression was more abundant on the surface of malignant blasts than on normal monocytes (Figure 2a). However, by comparing the density of CD47 expression between the two groups of patients that were either ecto-CRT ${ }^{\text {pos }}$ or ecto-CRT ${ }^{\text {neg }}$, we found that CD47 was weakly expressed among patients expressing ecto-CRT (Figure 2b). In conclusion, the 'eat me' signal ecto-CRT correlated inversely with the expression of the 'don't eat me' signal CD47 in AML. 
Table 1 Clinical and biological characteristics in $C R T^{\text {pos }}$ and $C R T^{\text {neg }}$ group of patients

\begin{tabular}{|c|c|c|c|c|}
\hline & All & $\mathrm{CRT}^{\mathrm{pos}}(n=10)$ & $\mathrm{CRT}^{\text {neg }}(n=10)$ & $P$-value \\
\hline $\begin{array}{l}\text { Sex }(\mathrm{m} / \mathrm{f}), n \\
\text { Median age at diagnosis, years (range) } \\
\text { Median blasts in blood, \% (range) } \\
\text { Median WBC }\left(\times 10^{9} / l\right)\end{array}$ & $\begin{array}{l}9 / 11 \\
62 \\
51 \\
27\end{array}$ & $\begin{array}{c}5 / 5 \\
62(26-77) \\
51(3-95) \\
35.5(2.8-215)\end{array}$ & $\begin{array}{c}4 / 6 \\
61(28-82) \\
48.5(5-85) \\
22(5-84)\end{array}$ & $\begin{array}{l}>0.5 \\
>0.5 \\
>0.5 \\
>0.5\end{array}$ \\
\hline $\begin{array}{l}\text { De novo } A M L, \mathrm{n} \\
\text { Of which } n \text { relapse } A M L \text { at the inclusion }\end{array}$ & $\begin{array}{r}16 \\
3\end{array}$ & $\begin{array}{l}8 \\
1\end{array}$ & $\begin{array}{l}7 \\
2\end{array}$ & $\begin{array}{l}>0.5 \\
>0.5\end{array}$ \\
\hline $\begin{array}{l}\text { Secondary } A M L \\
\text { MPS/MDS, } n \\
\text { Therapy related, } n\end{array}$ & $\begin{array}{l}2 \\
3\end{array}$ & $\begin{array}{l}1^{\mathrm{a}} \\
1^{\mathrm{b}}\end{array}$ & $\begin{array}{l}1^{\mathrm{a}} \\
2^{\mathrm{b}}\end{array}$ & $\begin{array}{l}>0.5 \\
>0.5\end{array}$ \\
\hline $\begin{array}{l}\text { FAB classification } \\
\text { M0 } \\
\text { M1 } \\
\text { M2 } \\
\text { M3 } \\
\text { M4 } \\
\text { M5 } \\
\text { M6, M7 }\end{array}$ & $\begin{array}{l}1 \\
3 \\
3 \\
1 \\
7 \\
5 \\
0\end{array}$ & $\begin{array}{l}0 \\
1 \\
2 \\
0 \\
4 \\
3 \\
0\end{array}$ & $\begin{array}{l}1 \\
2 \\
1 \\
1 \\
3 \\
2 \\
0\end{array}$ & $\begin{array}{l}>0.5 \\
>0.5 \\
>0.5 \\
>0.5 \\
>0.5 \\
>0.5 \\
>0.5\end{array}$ \\
\hline FLT3 ITD, $n$ & 4 & 3 & 1 & $>0.5$ \\
\hline $\begin{array}{l}\text { Cytogenetic profile } \\
\text { Favorable } \\
\text { Intermediate } \\
\text { Unfavorable } \\
\text { unknown }\end{array}$ & $\begin{array}{l}4 \\
9 \\
5 \\
2\end{array}$ & $\begin{array}{l}1 \\
6 \\
1 \\
2\end{array}$ & $\begin{array}{l}3 \\
3 \\
4 \\
0\end{array}$ & $\begin{array}{l}>0.5 \\
>0.5 \\
>0.5 \\
>0.5\end{array}$ \\
\hline
\end{tabular}

Abbreviations: AML, acute myeloid leukemia; ecto-CRT ${ }^{\text {neg }}$, no calreticulin expression; ecto-CRT ${ }^{\text {pos }}$, membrane expression of calreticulin; MPS/MDs, myeloproliferative/myelodysplastic syndrome

${ }^{a}$ Two patients with chronic myelomonocytic leukemia

${ }^{b}$ Previous chemotherapy and radiotherapy for throat and breast cancers
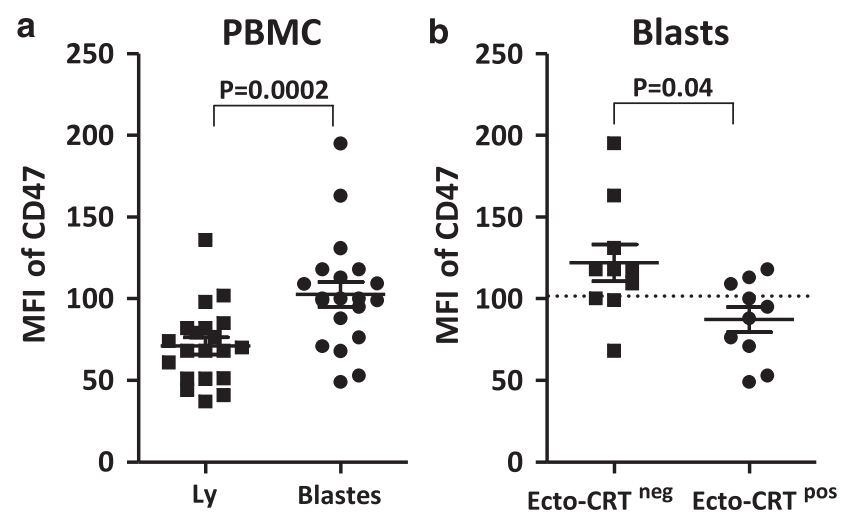

Figure 2 Ecto-CRT ${ }^{\text {pos }}$ blasts express less CD47 than ecto-CRT ${ }^{\text {neg }}$ blasts. (a) Cytofluorometric study of CD47 expression on circulating leukocytes from AML patients. The mean fluorescence intensity (MFI) of CD47 was determined by gating on $\mathrm{CD}_{4} 5^{\text {High }} \mathrm{CD}^{+}$lymphocytes (Ly) and CD45 ${ }^{\text {low }}$ blasts (blasts) and compared using a Wilcoxon's test. (b) As in a but comparing the MFI of CD47 on CD45 blasts between ecto-CRT ${ }^{\text {pos }}(n=10)$ and ecto-CRT ${ }^{\text {neg }}(n=10)$ AML patients. Statistical analysis was performed using the Mann-Whitney test. The dotted black bar represents the average MFI of CD47 on the entire cohort of AML patients $(n=20)$

Ecto-CRT is associated with an enhanced cellular immune response against tumor antigens. To determine the influence of ecto-CRT on anti-leukemic immune responses, we took advantage of $\mathrm{DC}$ derived from malignant blasts (Figure 3a). Such leukemic DCs (AML-DC) constitutively express tumor-associated antigens (TAAs)/LAAs as, for example, the antigen preferentially expressed in melanoma
(PRAME), the Wilms tumor gene 1 or the receptor for hyaluronic acid-mediated motility (CD168), which all can elicit antigen-specific T-cell immune responses. ${ }^{22-24}$ AML-DC can stimulate autologous T cells for proliferation, interferon- $\gamma$ (IFN $\gamma$ ) secretion and cytotoxicity. ${ }^{25}$ We comparatively assessed the capacity of autologous T cells to secrete IFN $\gamma$ on exposure to AML-DC in ecto-CRT ${ }^{\text {pos }}$ and ecto-CRT ${ }^{\text {neg }}$ patients. Purified $\mathrm{CD}^{+}{ }^{+} \mathrm{T}$ lymphocytes from ecto-CRT ${ }^{\text {pos }}$ patients did produce significant levels of IFN $\gamma$ in responses to AML-DC (Figures 3b and $\mathrm{c}$, middle panel, $P=0.0078$ ) but failed to do so in response to non-differentiated blasts (Figures $3 \mathrm{~b}$ and $\mathrm{c}$, middle panel, $P>0.05)$. This contrasts with the ecto-CRT ${ }^{\text {neg }}$ group, in which autologous T cells were unable to upregulate IFN $\gamma$ production in response to AML-DC (Figures $3 \mathrm{~b}$ and $\mathrm{c}$, right panel, $P>0.05$ ). Most HVs group exhibited a significant auto-reactivity of their $T$ cells against autologous monocyte-derived DCs (mDCs; Figures $3 \mathrm{~b}$ and $\mathrm{c}$, left panel, $P=0.0313$ ).

Altogether, these data suggest a significant link between ecto-CRT expression on malignant blasts at diagnosis and the induction of Th1 responses.

Impact of ecto-CRT on the clinical evolution of patients. Considering the small effective and the heterogeneity of our cohort, we could not expect a significant association to one or another evolution parameter. Accordingly, the overall survival of the patients enrolled in this study did not correlate significantly with ecto-CRT levels (Figure 4a), although there was a trend toward longer relapse-free survival for the ecto-CRT ${ }^{\text {neg }}$ group 
a
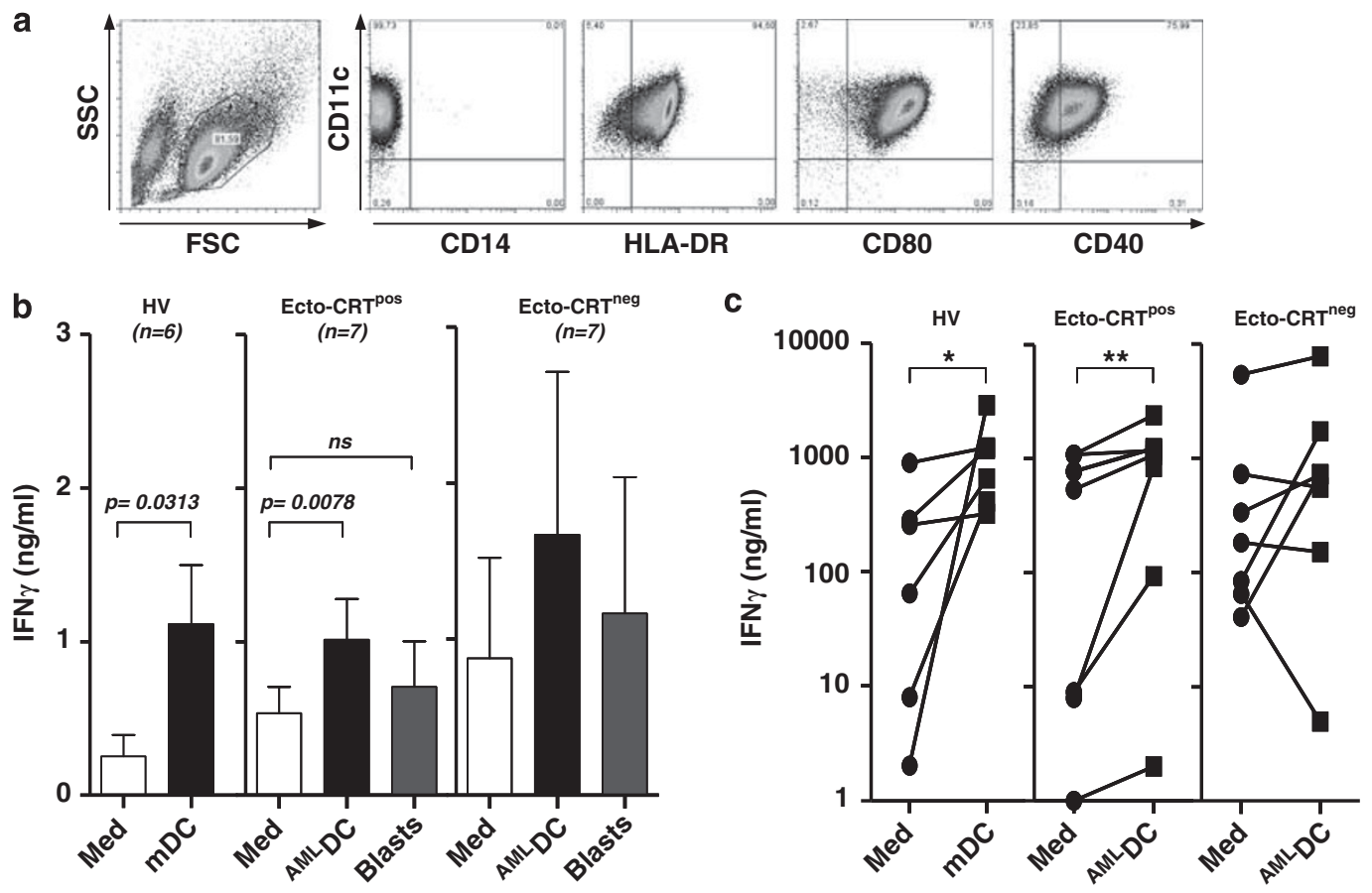

Figure 3 Ecto-CRT is associated with enhanced T lymphocyte responses to autologous leukemic DCs. (a) Representative flow cytometry analysis of LPS-matured AML blast-derived DCs ( ${ }^{\text {AML }} \mathrm{DC}$ ) defined as CD11c ${ }^{+} \mathrm{HLA}-\mathrm{DR}{ }^{+}$double-positive cells. Expression of CD80 and CD40 on AML-DC is also depicted. (b and c) Determination of IFN $\gamma$ levels in the supernatants from purified $\mathrm{CD}^{+}{ }^{+} \mathrm{T}$ lymphocytes co-cultured with autologous ${ }^{\mathrm{AML}} \mathrm{DC}$, autologous undifferentiated blast cells at diagnosis or medium as control. Autologous monocyte-derived DCs ( $\mathrm{mDC}$ ) from HVs were co-cultured with purified autologous $\mathrm{CD} 3^{+} \mathrm{T}$ lymphocytes or medium as control. Statistical analysis was performed using a Wilcoxon matched-pairs test. Results were either plotted as means \pm S.E.M. b or on a patient-by-patient basis $\mathbf{c}$. ns, nonsignificant

(Figure 4b). As expected, ${ }^{21}$ we found a trend for accelerated relapses in patients with high CD47 expression (mean fluorescence intensity (MFI) $\geq 100$; median relapsefree survival for patient reaching complete remission after induction chemotherapy 11.23 months versus unreached for patients with low CD47 expression $(\mathrm{MFI}<100)$ ), although our cohort was too small to detect a significant effect of CD47 $(P=5229)$. Five patients relapsed in the ecto-CRT ${ }^{\text {neg }}$ group $(62.5 \%)$ versus two in the ecto-CRT ${ }^{\text {pos }}$ group (28.5\%) with a median follow-up of 40 months among patients who had achieved a complete response after induction chemotherapy ( $n=7$ for ecto-CRT ${ }^{\text {pos }}$ group and $n=8$ for ecto-CRT ${ }^{\text {neg }}$ group, Table 2). This trend in the relapse-free survival for ecto-CRT ${ }^{\text {pos }}$ patients prompts us to extend this study to a larger cohort.

\section{Discussion}

This clinical study has explored the putative link between CRT cell surface expression and anthracycline-based chemotherapy in AML patients. Unexpectedly, we failed to produce evidence that anthracyclines would induce CRT on the surface of malignant blasts (Figure 1). Indeed, in half of the AML cases, leukemic cells spontaneously exposed CRT on their surface, correlating with the constitutive phosphorylation of elF2 $\alpha$ (Figure 1d). This suggests that an ER stress response that culminates in CRT exposure is constitutively activated in a fraction of AML. Half of patients' tumor cells have activated this crucial mechanism favoring their uptake by antigen-presenting cells (APCs). ${ }^{3-5}$ This hypothesis is strengthened by the observation that CD47 molecules are less abundant on the surface of ecto-CRT ${ }^{\text {pos }}$ than on ecto-CRT ${ }^{\text {neg }}$ blasts (Figure 2). Indeed, the reduced expression of the 'don't eat me' signal (CD47), together with the enhanced expression of the 'eat me' signal (ecto-CRT), suggests that leukemic cells are efficiently engulfed by APCs that then trigger an immune response against TAAs. Recent reports have highlighted the fact that $\mathrm{SIRP} \alpha$ could represent a myeloid sensor for the 'self' molecule CD47. ${ }^{26}$ SIRP $\alpha$ is an inhibitory immunoreceptor that is selectively expressed by myeloid lineage cells (macrophages, granulocytes and myeloid DC), as well as neuronal cells. ${ }^{27-29}$ The ligation of SIRP $\alpha$ on macrophages (or other phagocytic cells expressing this molecule) by CD47 expressed on non-phagocytic cells generates an SHP-1-dependent inhibitory signal that suppresses phagocytosis. ${ }^{30}$ Thus, low expression of CD47 on malignant blasts should be correlated with a better engulfment by SIRP $\alpha$-expressing cells. Moreover, ecto-CRT can favor the uptake of dying cells by DC, leading to efficient T-cell priming in vivo. $^{3}$ It is still unknown whether the candidate CRT receptors CD91 and scavenger receptor class-A are required for the DC-specific engulfment of CRT-exposing tumor cells. ${ }^{31}$ Taken together, these data provide a rational to suggest that in AML, leukemic cells that express ecto-CRT and low levels of CD47 could be engulfed by APCs thus favoring an adaptive immune response against tumor antigens. Interestingly, in the subgroup of patients who failed to express ecto-CRT at the baseline level, anthracyclines were unable to induce ecto-CRT either in vivo (Figure 1d) or in vitro (data not shown). This suggests that these tumor 

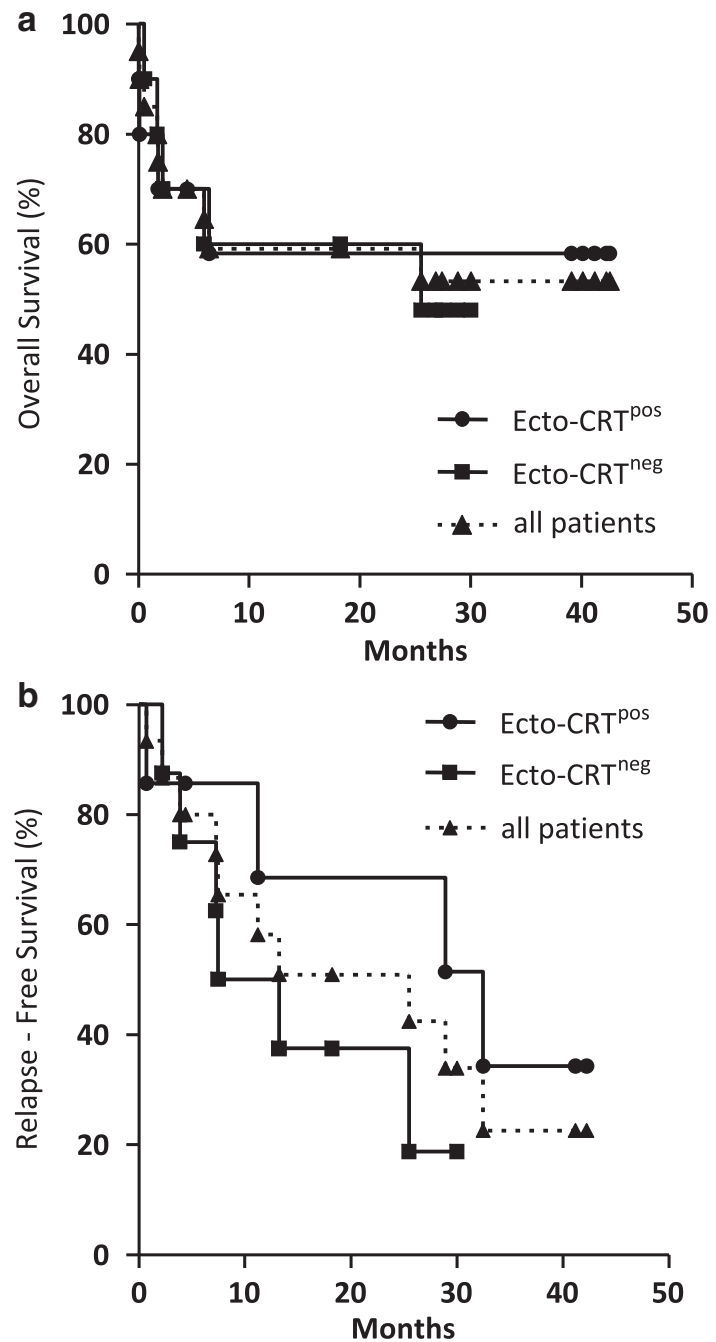

Figure 4 Correlation of ecto-CRT exposure and patient evolution. (a) Overall survival. (b) Relapse-free survival for patients who achieved complete remission after intensive chemotherapy $(n=15)$. The difference between ecto-CRT ${ }^{\text {pos }}$ and ecto-CRT $^{\text {neg }}$ is not statistically significant (log-rank Mantel-Cox test; $P=0.5008$ )

cells have a defective CRT exposure pathway (Figure 1d) that could not be induced and/or restored by induction chemotherapy. In analogy, a previous observation was made on neuroblastoma cells that were also refractory to anthracyclin-induced CRT exposure unless the ER $\mathrm{Ca}^{2+}$ channel SERCA was blocked. ${ }^{32}$

Although we were unable to identify any effect of anthracyclines on CRT exposure on leukemic cells, we tested the hypothesis that ecto-CRT might be linked to antitumor Th1 immune responses. As shown in Figure 3 , this link exists. Indeed, purified T lymphocytes from the ecto-CRT ${ }^{\text {pos }}$ group of patients were capable of secreting IFN $\gamma$ in response to autologous leukemic DCs, while ecto-CRT ${ }^{\text {neg }}$ group of patients failed to do so. It is to be noted that lymphocytes were isolated at diagnosis before any treatment, demonstrating that this antitumor immune response occurred 'naturally' (that is before treatment) in AML. How can the differences between ecto-CRT ${ }^{\text {pos }}$ and ecto-CRT ${ }^{\text {neg }}$ patients with respect to the antitumor immune response be explained? The 'eat me'
Table 2 Clinical outcome

\begin{tabular}{lccc}
\hline & All & $\begin{array}{c}\text { CRT (+) } \\
(\boldsymbol{n}=\mathbf{1 0})\end{array}$ & $\begin{array}{c}\text { CRT (-) } \\
(\boldsymbol{n}=\mathbf{1 0})\end{array}$ \\
\hline $\begin{array}{l}\text { Intensive chemotherapy, } n \\
\text { CR, } n\end{array}$ & 18 & 9 & 9 \\
& 15 & 7 & 8 \\
$\begin{array}{l}\text { Consolidation in CR 1 } \\
\quad \text { Chemotherapy only, } n\end{array}$ & 11 & 5 & \\
$\quad$ HSC allograft, $n$ & 4 & 2 & 2 \\
Relapse, $n$ & 6 & 2 & 4 \\
$\begin{array}{l}\text { Death total, n } \\
\quad \text { Death without CR, } n\end{array}$ & 8 & 4 & 4 \\
$\quad \begin{array}{l}\text { Death after relapse, } n \\
\text { Death of other cause, } n\end{array}$ & 5 & 3 & 2 \\
$\begin{array}{l}\text { Median follow-up, } \\
\text { month (range) }\end{array}$ & $13(1-42)$ & $29(1-42)$ & $10.3(2-30)$ \\
$\begin{array}{l}\text { Relapse-free survival in } \\
\text { (CR) patients }(n=15):\end{array}$ & & 32.5 & 10.3 \\
median, month & & & \\
\hline
\end{tabular}

Abbreviations: $\mathrm{CR}$, complete remission; HSC, hematopoietic stem cell ${ }^{a}$ Death of infectious cause during consolidation course

*Relapse-free survival: survival without relapse for patients who achieved CR $(n=15)$

and 'don't eat me' signals expressed on the surface of tumor cells might have a crucial role in determining the nature of APC, thus ultimately influencing the polarization of the immune response. Indeed, it is well accepted that distinct DC subtypes not only control immunity but also regulate the advent and the type of responses against self and non-self. ${ }^{33}$ In humans, some DC sub-populations have been proposed to secrete high levels of IL-12, thereby favoring Th1 polarization. ${ }^{34}$ Human DC selectively expressing 6-sulfo LacNAc, an O-linked carbohydrate modification of PSGL-1, have recently been identified in the blood and have been nicknamed 'slanDC' in reference to their specific marker (6-sulfo LacNAc). ${ }^{35,36}$ SlanDC account for the majority of DC in human blood (0.6-2\% of PBMCs) and have a phenotype (6-sulfo LacNAc +, CD1C-, CD11c+, CD16+, CD142, $\mathrm{C} 5 \mathrm{aR}+$ and CD45RA +) that differs from that of previously described DC sub-populations. ${ }^{37}$ SlanDC are the quantitatively most abundant IL-12p70-producing cells among blood leukocytes. These findings emphasize the probable role of slanDC in the induction and perpetuation of inflammation, as this is also suggested by the high frequency of slanDC in diseases characterized by local Th1-dominated inflammatory response, such as psoriasis vulgaris and rheumatoid arthritis. Interestingly, the maturation of and IL-12 production by slanDC is controlled by CD47 expressed on erythrocytes and SIRP $\alpha$ expressed on slanDC. ${ }^{35}$ Hence, slanDC might represent a good candidate for the APC that engulfs CD47 $7^{\text {low }}$ leukemia cells. Nonetheless, the expression of CRT receptors (such as CD91 and scavenger receptor class-A), on slanDC, remains to be studied. It should be noted that another human DC subtype, DC NK lectin group receptor- $1^{+}$blood DC antigen $-3^{+}$DCs has recently been identified. ${ }^{38}$ This DC subtype efficiently internalizes antigenic material from necrotic cells, produces high levels of IL-12 and cross-presents exogenous antigens to $\mathrm{CD}^{+} \mathrm{T}$ cells, thus representing the human equivalent of murine $\mathrm{CD} 8 \alpha^{+} \mathrm{DC}{ }^{38}$ However, the relationship between these $\mathrm{DC}$ subtypes and their capacity to internalize tumor cells expressing ecto-CRT remains elusive. 
To conclude, we have identified cell surface exposure of CRT on primary blasts from approximately half of the AML patients. This CRT exposure occurs before chemotherapy and is not further enhanced by anthracycline-based chemotherapy. Conversely, half of the patients' blasts lacked CRT exposure both before and after anthracyline treatment. We demonstrated for the first time a link between ecto-CRT on the surface of malignant blasts and the secretion of IFN $\gamma$ by autologous $\mathrm{T}$ lymphocytes confronted with them. On the basis of these encouraging results, we will launch a large prospective study to determine the prognostic and predictive impact of ecto-CRT expression and that of its surrogate marker, elF $2 \alpha$ phosphorylation.

\section{Patients and Methods}

Patients. Twenty patients, who were diagnosed with AML, were consecutively admitted in the Hematology Department of the Institut Gustave Roussy in Villejuif, France, between March 2008 and March 2009. Informed consent was obtained, according to the Declaration of Helsinki, and the study was approved by the local ethics committee (Comité de Protection des Personnes (CPP) Hôpital Bicêtre CALEX protocol, $n^{\circ}$ ID RCB 2007-A01074-49, date 29 February 2008). The main clinical and biological characteristics of the patients are summarized in Table 3. Induction chemotherapy comprised one anthracycline (idarubicine or daunorubicine) associated with cytarabine (except for two patients: one not eligible for an intensive chemotherapy, and one who died in intensive care unit before initiation of the treatment), followed by one to four courses of consolidation. One patient, who was diagnosed with promyelocytic leukemia, also received ATRA. An allograft of hematopoietic stem cells was performed for eligible patients (relapse situation and high risk of relapse, based on cytogenetic and biomolecular results), for whom a (genotypically or phenotypically) compatible donor was found.

Blood samples. Peripheral blood samples were obtained before the onset of chemotherapy in all patients. A second sample was drawn 2 to $6 \mathrm{~h}$ after the initiation of the intravenous chemotherapy. PBMC were separated on a Ficoll-gradient.

Flow cytometry. PBMCs were first fixed briefly in $0.25 \%$ paraformaldehyde on ice. Cells were directly labeled with an anti-CD45 monoclonal antibody (coupled to APC, BD Biosciences, Le Pont de Claix, France). CD45 is highly expressed on normal hematopoietic cells, yet poorly expressed on malignant blasts (CD45 dim). The labeling of the membrane CRT was performed in two-step procedure: (i) incubation with a rabbit anti-CRT antibody (Ozyme, Saint-Quentin-en-Yvelines, France) (or rabbit serum as an isotypic control), then, after a washing step in cold PBS, (ii) labeling with an anti-rabbit immunoglobulin coupled to FITC (BD Biosciences). All these steps were performed on ice. The labeled PBMCs were analyzed on a FACS Calibur cytofluorometer (Becton Dickinson, Le Pont de Claix, France) with a simultaneous discrimination of the live-dead cells using 7AAD (amino-actinomycin D, BD Biosciences). CD47 expression was measured using an anti CD47-phycoerythrine conjugate (BD Biosciences) while gating on $\mathrm{CD} 45^{\text {high }}$ and CD45 ${ }^{\text {dim }}$ cells in order to discriminate normal from blast cells. FACS data were analyzed with the help of FlowJo software (Tree Star, Inc., Ashland, OR, USA).

ELISA assay for the dosage of soluble CRT in sera of patients. A sandwich ELISA assay was performed to detect CRT in the sera of patients before and after chemotherapy. Briefly, anti-CRT polyclonal (rabbit anti-CRT, Ozyme) diluted to $1 /$ $1000^{\mathrm{e}}$ in PBS ( $\mathrm{pH}=7.2$ ) supplemented with $100 \mathrm{mM}$ bicarbonate, was incubated in 96 well Maxisorp plates at $4{ }^{\circ} \mathrm{C}$ overnight. After washing (PBS supplemented with $0.05 \%$ Tween), PBS 2\% human serum albumin was added for $1 \mathrm{~h}$ for saturation. After washing, samples (diluted 1: 10 in PBS plus 2\% albumin) were added to the wells for $2 \mathrm{~h}$ at room temperature. After washing, a secondary anti-CRT (mouse anti-CRT, Abcam, Paris, France; dilution $1 / 5000^{\mathrm{e}}$ ) was added ( $1 \mathrm{~h}$ at room temperature). A goat anti-mouse antibody coupled to horseradish peroxidase (Jackson Immunoresearch, Marseille, France; dilution $1 / 5000^{\circ}$ ) was added for $1 \mathrm{~h}$ at room temperature and subsequently washed. Revelation was done using TMB substrate (tetramethylbenzidine OptEIA, BD Biosciences). The reaction was stopped with $50 \mu \mathrm{l}$ of $1 \mathrm{M} \mathrm{H}_{2} \mathrm{SO}_{4}$, and the optical density was measured at $450 \mathrm{~nm}$. Patient samples were analyzed in triplicate and compared with sera from HVs.
Table 3 Baseline clinical and biological characteristics of the patients

\section{Variable}

\begin{tabular}{|c|c|}
\hline $\begin{array}{l}\text { Age } \\
\quad<50 \text { years } \\
\geq 50 \text { years } \\
\text { Median (years) } \\
\text { Range (years) }\end{array}$ & $\begin{array}{c}7(35 \%) \\
13(65 \%) \\
62 \\
26-82\end{array}$ \\
\hline $\begin{array}{l}\text { Sex } \\
\quad \text { Male } \\
\text { Female }\end{array}$ & $\begin{array}{r}9(45 \%) \\
11(55 \%)\end{array}$ \\
\hline $\begin{array}{l}\text { Peripheral-blood white cell count } \\
<30.000 / \mathrm{mm}^{3} \\
\geq 30.000 / \mathrm{mm}^{3} \\
\text { Median }\left(10^{9} \mathrm{cells} / \mathrm{l}\right) \\
\text { Range }\left(10^{9} \text { cells } / \mathrm{l}\right)\end{array}$ & $\begin{array}{c}10(50 \%) \\
10(50 \%) \\
180 \\
2.8-215\end{array}$ \\
\hline $\begin{array}{l}\text { Blasts peripheral blood } \\
\text { Median (\%) } \\
\text { Range }(\%)\end{array}$ & $\begin{array}{c}51 \\
3-85\end{array}$ \\
\hline $\begin{array}{l}\text { De novo } A M L, \mathrm{n} \\
\text { Of which } n \text { relapse } A M L \text { at the inclusion }\end{array}$ & $\begin{array}{r}16(80 \%) \\
3(15 \%)\end{array}$ \\
\hline $\begin{array}{l}\text { Secondary } A M L \\
\text { MPS/MDS, } n \\
\text { Therapy related, } n\end{array}$ & $\begin{array}{l}2(10 \%) \\
3(15 \%)\end{array}$ \\
\hline $\begin{array}{l}\text { FAB classification } \\
\text { AML 0 } \\
\text { AML 1 } \\
\text { AML } 2 \\
\text { AML 3 } \\
\text { AML 4 } \\
\text { AML 5 } \\
\text { AML 6 } \\
\text { AML } 7\end{array}$ & $\begin{array}{l}1(5 \%) \\
3(15 \%) \\
3(15 \%) \\
1(5 \%) \\
6(30 \%) \\
6(30 \%) \\
0(0 \%) \\
0(0 \%)\end{array}$ \\
\hline $\begin{array}{l}\text { Cytogenetic profile } \\
\text { Favorable } \\
\text { Intermediate } \\
\text { Unfavorable } \\
\text { Missing data }\end{array}$ & $\begin{array}{l}4(20 \%) \\
9(45 \%) \\
5(25 \%) \\
2(10 \%)\end{array}$ \\
\hline $\begin{array}{l}\text { Molecular characteristics } \\
\text { Isolated FLT3-ITD } \\
\text { FLT3-ITD and NPM\# } \\
\text { AML1/RUNX1 }\end{array}$ & $\begin{array}{l}3(15 \%) \\
1(5 \%) \\
1(5 \%)\end{array}$ \\
\hline
\end{tabular}

Abbreviations: AML, acute myeloid leukemia; AML1/RUNX1, runt-related transcription factor 1; FAB, Franco-Americano-British classification; FLT3-ITD, FLT3 internal tandem duplication; MPS/MDs, myeloproliferative/ myelodysplastic syndrome; NPM, nuclephosmine; WBC, white blood count \#One patient presented a NPM (nuclephosmine) mutation, but associated with FLT3-ITD

Leukemic DCs. DCs were derived from PBMC as previously described. ${ }^{39}$ Briefly, PBMCs were incubated at $37^{\circ} \mathrm{C}$ in a flask at $1.10^{6} \mathrm{cells} / \mathrm{cm}^{2}$ in culture medium (AIM-V, Invitrogen, Cergy Pontoise, France); after $2 \mathrm{~h}$, the supernatant was discarded, and the adherent cells (mostly blasts cells) were cultured for 4 days in AIM-V medium containing IL-4 (200 IU/ml, Cellgenix, Clermont L'Herault, France) and GM-CSF (1000 IU $/ \mathrm{ml}$, Cellgenix). Lipopolysaccharide $(1 \mu \mathrm{g} / \mathrm{ml}$, Sigma, Lyon, France) was added on the last day before collection to induce DCs maturation. The cells were collected and their immunophenotype was checked by immunofluorescene and flow cytometry to confirm the presence of DC markers (anti-CD11c PC7, anti-HLA-DR Pacific Blue, anti-CD40 FITC, anti-CD80 PE, all from BD Bioscience).

Isolation of T lymphocytes. PBMCs from the diagnosis (before treatment) were frozen after collection and isolation by Ficoll density gradient centrifugation. After thawing, cells were labeled with anti-CD3 antibody (coupled to FITC, BD Bioscience), and their viability was assessed using 7AAD. The labeled cells were 
washed and sorted using a cell sorter cytometer (MoFlow, Beckman, Villepinte, France), while discriminating the cells based on their size, granularity and fluorescence $\left(\mathrm{CD}^{+}\right.$and $\left.7 \mathrm{AAD}^{-}\right)$allowing for the isolation of $>95 \%$ pure $\mathrm{T}$ lymphocytes.

In vitro stimulation of T lymphocytes. The leukemic DCs were incubated with autologous T lymphocytes (LT) in 96-wells plates in triplicates, at a $L T / D C$ ratio of 10 to 1 . IL-2 (10 IU/ml, Proleukine from Novartis, Rueil-Malmaison, France) and IL-7 ( $5 \mathrm{ng} / \mathrm{ml}$, R\&D system, Minneapolis, MN, USA) were added in the medium. As a control, mDCs from HVs were incubated with autologous T lymphocytes. After 2 days, supernatants were collected and frozen at $-80^{\circ} \mathrm{C}$ until measurement of IFN $\gamma$ by ELISA. We managed to realize this stimulation protocol for 15 of the 20 patients ( $n=8$ for the ecto-CRT-negative group and $n=7$ for the ecto-CRT-positive group of patients); for the five other patients, we were unable to derive $\mathrm{DC}$ from blasts or failed to obtain a sufficient number of T lymphocytes from peripheral blood because of a major lymphopenia at diagnosis. The control experiment was performed on five HVs. Statistical analyses were performed using the Wilcoxon test for non-parametric paired values, with the help of the Graphpad Prism 5 software (GraphPad Software, Inc., La Jolla, CA, USA).

Western blot analysis. Frozen blasts were thawed and washed with PBS before lyses as previously described. ${ }^{40}$ The protein content was measured using the Protein Assay Kit (Bio-Rad, Marnes-la-Coquette, France) following the manufacture's instruction and $50 \mu \mathrm{g}$ of protein were separated onto NuPAGE gels (Invitrogen) and transferred to Immobilion-PVDF membranes (Millipore Corp., Billerica, MA, USA). The membranes were incubated for $1 \mathrm{~h}$ in TBS-Tween 20 $(0.05 \%)$ containing $5 \%$ BSA. Primary antibodies specific for phosphorylated elF2 $\alpha$ (Cell Signaling Technology, Danvers, MA, USA) and elF2 $\alpha$ (Cell Signaling Technology) were incubated overnight at $4{ }^{\circ} \mathrm{C}$ and revealed with the appropriate horseradish peroxidase-labeled secondary antibodies (SouthernBiotech, Birmingham, AL, USA) by means of chemoluminiscent substrate (Pierce, Rockford, IL, USA).

Confocal microscopy. Primary cells from an AML patient have been washed with PBS before immunostaining using anti-CD45 antibody (FITC coupled from BD Bioscience). The cells have been washed with PBS and subsequently fixed with $0.25 \%$ of PFA before staining of cell surface CRT using mouse monoclonal antibody (clone fmc75, ab22683, Abcam) followed by anti-mouse AlexaFluor 568 (Molecular Probes (Cergy Pontoise, France), Invitrogen) in PBS supplemented with 5\% BSA. The nuclei were stained with DAPI before image acquisition by means of a TSCSPE confocal microscope (Leica Microsystems GmbH, Wetzlar, Germany) equipped with a $63 X / 1.15$ objective (Olympus America, Center Valley, PA, USA). Signals from different probes were acquired in sequential scan mode and overlays have been done with Photoshop.

\section{Conflict of Interest}

The authors declare no conflict of interest.

Acknowledgements. We acknowledge support from la Fondation de France contre la Leucémie, Institut National de la Santé et de la Recherche Médicale (INSERM), Institut Gustave Roussy, I'Institut National du Cancer (INCa), Ligue Nationale contre le Cancer (équipe labellisé by $L$ Zitvogel), Association pour la Recherche sur le Cancer (ARC), Fondation pour la Recherche Médicale en France (FRM). TP is supported by the Swedish Cancer Society, the Children's Cancer Society, the Swedish Royal Academy of Sciences and the Åke Wiberg foundation.

1. Banchereau J, Palucka AK. Dendritic cells as therapeutic vaccines against cancer. Nat Rev Immunol 2005; 5: 296-306.

2. Casares N, Pequignot MO, Tesniere A, Ghiringhelli F, Roux S, Chaput N et al. Caspasedependent immunogenicity of doxorubicin-induced tumor cell death. J Exp Med 2005; 202: 1691-1701.

3. Obeid M, Tesniere A, Ghiringhelli F, Fimia GM, Apetoh L, Perfettini JL et al. Calreticulin exposure dictates the immunogenicity of cancer cell death. Nat Med 2007; 13: 54-61.

4. Ghiringhelli F, Apetoh L, Tesniere A, Aymeric L, Ma Y, Ortiz C et al. Activation of the NLRP3 inflammasome in dendritic cells induces IL-1beta-dependent adaptive immunity against tumors. Nat Med 2009; 15: 1170-1178.
5. Apetoh L, Ghiringhelli F, Tesniere A, Obeid M, Ortiz C, Criollo A et al. Toll-like receptor 4-dependent contribution of the immune system to anticancer chemotherapy and radiotherapy. Nat Med 2007; 13: 1050-1059.

6. Moenner $\mathrm{M}$, Pluquet $\mathrm{O}$, Bouchecareilh $\mathrm{M}$, Chevet $\mathrm{E}$. Integrated endoplasmic reticulum stress responses in cancer. Cancer Res 2007; 67: 10631-10634.

7. Panaretakis T, Joza N, Modjtahedi N, Tesniere A, Vitale I, Durchschlag M et al. The cotranslocation of ERp57 and calreticulin determines the immunogenicity of cell death. Cell Death Differ 2008; 15: 1499-1509.

8. Panaretakis T, Kepp O, Brockmeier U, Tesniere A, Bjorklund AC, Chapman DC et al. Mechanisms of pre-apoptotic calreticulin exposure in immunogenic cell death. Embo $\mathrm{J}$ 2009; 28: 578-590.

9. Kapp M, Stevanovic S, Fick K, Tan SM, Loeffler J, Opitz A et al. CD8+ T-cell responses to tumor-associated antigens correlate with superior relapse-free survival after allo-SCT. Bone Marrow Transplant 2009; 43: 399-410.

10. Robin M, Andreu-Gallien J, Schlageter MH, Bengoufa D, Guillemot I, Pokorna K et al. Frequent antibody production against RARalpha in both APL mice and patients. Blood 2006; 108: 1972-1974.

11. Montagna D, Maccario R, Locatelli F, Montini E, Pagani S, Bonetti F et al. Emergence of antitumor cytolytic $T$ cells is associated with maintenance of hematologic remission in children with acute myeloid leukemia. Blood 2006; 108: 3843-3850.

12. Szczepanski MJ, Szajnik M, Czystowska M, Mandapathil M, Strauss L, Welsh A et al. Increased frequency and suppression by regulatory $\mathrm{T}$ cells in patients with acute myelogenous leukemia. Clin Cancer Res 2009; 15: 3325-3332.

13. Gao AG, Lindberg FP, Dimitry JM, Brown EJ, Frazier WA. Thrombospondin modulates alpha $v$ beta 3 function through integrin-associated protein. J Cell Biol 1996; 135: 533-544.

14. Lindberg FP, Bullard DC, Caver TE, Gresham HD, Beaudet AL, Brown EJ. Decreased resistance to bacterial infection and granulocyte defects in IAP-deficient mice. Science 1996; 274: 795-798.

15. Miyashita $M$, Ohnishi $H$, Okazawa $H$, Tomonaga $H$, Hayashi $A$, Fujimoto TT et al. Promotion of neurite and filopodium formation by CD47: roles of integrins, Rac, and Cdc42. Mol Biol Cell 2004; 15: 3950-3963.

16. Reinhold MI, Lindberg FP, Kersh GJ, Allen PM, Brown EJ. Costimulation of T cell activation by integrin-associated protein (CD47) is an adhesion-dependent, CD28-independent signaling pathway. J Exp Med 1997; 185: 1-11.

17. Jiang $P$, Lagenaur $C F$, Narayanan V. Integrin-associated protein is a ligand for the $P 84$ neural adhesion molecule. J Biol Chem 1999; 274: 559-562.

18. Oldenborg PA, Zheleznyak A, Fang YF, Lagenaur CF, Gresham HD, Lindberg FP. Role of CD47 as a marker of self on red blood cells. Science 2000; 288: 2051-2054.

19. Blazar BR, Lindberg FP, Ingulli E, Panoskaltsis-Mortari A, Oldenborg PA, lizuka K et al. CD47 (integrin-associated protein) engagement of dendritic cell and macrophage counterreceptors is required to prevent the clearance of donor lymphohematopoietic cells. J Exp Med 2001; 194: 541-549.

20. Jaiswal S, Jamieson CH, Pang WW, Park CY, Chao MP, Majeti R et al. CD47 is upregulated on circulating hematopoietic stem cells and leukemia cells to avoid phagocytosis. Cell 2009; 138: 271-285.

21. Majeti R, Chao MP, Alizadeh AA, Pang WW, Jaiswal S, Gibbs Jr KD et al. CD47 is an adverse prognostic factor and therapeutic antibody target on human acute myeloid leukemia stem cells. Cell 2009; 138: 286-299.

22. Choudhury BA, Liang JC, Thomas EK, Flores-Romo L, Xie QS, Agusala K et al. Dendritic cells derived in vitro from acute myelogenous leukemia cells stimulate autologous, antileukemic T-cell responses. Blood 1999; 93: 780-786.

23. Kohler T, Plettig R, Wetzstein W, Schmitz M, Ritter M, Mohr B et al. Cytokine-driven differentiation of blasts from patients with acute myelogenous and lymphoblastic leukemia into dendritic cells. Stem Cells 2000; 18: 139-147.

24. Li L, Reinhardt P, Schmitt A, Barth TF, Greiner J, Ringhoffer M et al. Dendritic cells generated from acute myeloid leukemia (AML) blasts maintain the expression of immunogenic leukemia associated antigens. Cancer Immunol Immunother 2005; 54: 685-693.

25. Cignetti A, Vallario A, Roato I, Circosta P, Allione B, Casorzo L et al. Leukemia-derived immature dendritic cells differentiate into functionally competent mature dendritic cells that efficiently stimulate T cell responses. J Immunol 2004; 173: 2855-2865.

26. van den Berg TK, van der Schoot CE. Innate immune 'self' recognition: a role for CD47-SIRPalpha interactions in hematopoietic stem cell transplantation. Trends Immunol 2008; 29: 203-206.

27. Adams S, van der Laan LJ, Vernon-Wilson E, Renardel de Lavalette C, Dopp EA, Dijkstra $C D$ et al. Signal-regulatory protein is selectively expressed by myeloid and neuronal cells. J Immunol 1998; 161: 1853-1859.

28. Barclay AN, Brown MH. The SIRP family of receptors and immune regulation. Nat Rev Immunol 2006; 6: 457-464.

29. van Beek EM, Cochrane F, Barclay AN, van den Berg TK. Signal regulatory proteins in the immune system. J Immunol 2005; 175: 7781-7787.

30. Okazawa H, Motegi S, Ohyama N, Ohnishi H, Tomizawa T, Kaneko Y et al. Negative regulation of phagocytosis in macrophages by the CD47-SHPS-1 system. J Immunol 2005; 174: 2004-2011.

31. Gardai SJ, McPhillips KA, Frasch SC, Janssen WJ, Starefeldt A, Murphy-Ullrich JE et al. Cell-surface calreticulin initiates clearance of viable or apoptotic cells through transactivation of LRP on the phagocyte. Cell 2005; 123: 321-334. 
32. Tufi R, Panaretakis T, Bianchi K, Criollo A, Fazi B, Di Sano F et al. Reduction of endoplasmic reticulum $\mathrm{Ca} 2+$ levels favors plasma membrane surface exposure of calreticulin. Cell Death Differ 2008; 15: 274-282.

33. Coquerelle $\mathrm{C}$, Moser M. DC subsets in positive and negative regulation of immunity. Immunol Rev 2010; 234: 317-334.

34. Trinchieri G. Interleukin-12 and the regulation of innate resistance and adaptive immunity Nat Rev Immunol 2003; 3: 133-146.

35. Schakel K, von Kietzell M, Hansel A, Ebling A, Schulze L, Haase M et al. Human 6-sulfo LacNAc-expressing dendritic cells are principal producers of early interleukin-12 and are controlled by erythrocytes. Immunity 2006; 24: 767-777.

36. Wehner R, Lobel B, Bornhauser M, Schakel K, Cartellieri M, Bachmann M et al. Reciprocal activating interaction between 6 -sulfo LacNAc+ dendritic cells and NK cells. Int J Cancer 2009; 124: 358-366

37. Schakel K, Mayer E, Federle C, Schmitz M, Riethmuller G, Rieber EP. A nove dendritic cell population in human blood: one-step immunomagnetic isolation by a specific $\mathrm{mAb}$ (M-DC8) and in vitro priming of cytotoxic T lymphocytes. Eur J Immunol 1998; 28: 4084-4093.
38. Poulin LF, Salio M, Griessinger E, Anjos-Afonso F, Craciun L, Chen $J \mathrm{~L}$ et al. Characterization of human DNGR-1+ BDCA3+ leukocytes as putative equivalents of mouse CD8alpha+ dendritic cells. J Exp Med 2010; 207: 1261-1271.

39. Li L, Giannopoulos K, Reinhardt P, Tabarkiewicz J, Schmitt A, Greiner J et al. Immunotherapy for patients with acute myeloid leukemia using autologous dendritic cells generated from leukemic blasts. Int J Oncol 2006; 28: 855-861.

40. Gonzalez-Polo RA, Carvalho G, Braun T, Decaudin D, Fabre C, Larochette N et al. PK11195 potently sensitizes to apoptosis induction independently from the peripheral benzodiazepin receptor. Oncogene 2005; 24: 7503-7513.

Cell Death and Disease is an open-access journal published by Nature Publishing Group. This work is licensed under the Creative Commons Attribution-Noncommercial-No Derivative Works 3.0 Unported License. To view a copy of this license, visit http://creativecommons.org/licenses/by-nc-nd/3.0/ 